\title{
It takes all sorts to make a world: geographical differences and the future perspective of molecular testing in non-small cell lung cancer
}

\author{
Pietro Bertoglio ${ }^{1}$, Lorena Costardi ${ }^{2,3}$, Andrea Viti ${ }^{1}$, Enrico Ruffini ${ }^{2,3}$, Francesco Guerrera ${ }^{2,3}$ \\ ${ }^{1}$ Division of Thoracic Surgery, IRCCS Sacro Cuore-Don Calabria Hospital, Negrar, Verona, Italy; ${ }^{2}$ Department of Thoracic Surgery, A.O.U. Città \\ Della Salute e Della Scienza di Torino, Turin, Italy; ${ }^{3}$ Department of Surgical Sciences, University of Torino, Torino, Italy \\ Correspondence to: Francesco Guerrera, MD. Department of Thoracic Surgery, Azienda Ospedaliera Universitaria Città della Salute e della Scienza di \\ Torino; Department of Sugical Science, University of Torino, Corso Dogliotti, 1410126 Torino, Italy. Email: fra.guerrera@gmail.com. \\ Provenance and Peer Review: This article was commissioned by the editorial office, fournal of Thoracic Disease. The article did not undergo external peer \\ review. \\ Comment on: Liang W, Cai K, Chen C, et al. Society for Translational Medicine consensus on postoperative management of EGFR-mutant lung \\ cancer (2019 edition). Transl Lung Cancer Res 2019;8:1163-73.
}

Submitted Apr 20, 2020. Accepted for publication May 08, 2020.

doi: 10.21037/jtd-2020-49

View this article at: http://dx.doi.org/10.21037/jtd-2020-49

Lung cancer is a global challenge with a high number of deaths every year (1). Development in lung cancer research should allow us to better define risk groups and to offer an always more patient-tailored therapy.

In the last years, adenocarcinoma has become the most frequent histotype of non-small cell lung cancer (NSCLC). In 2015 the World Health Organization (2) reviewed the histological classification identifying different patterns with different clinical behaviors both in terms of overall survival and disease-free survival; these differences in long term outcomes could be justified by a different incidence in molecular features between these subtypes. Based on all these peculiarities, the association of histological and molecular features delineates further subgroups of NSCLC which have different prognostic outcomes and therapeutic options. Despite these advances towards a molecularoriented therapy approach, data do not show homogeneous results and the use of molecular testing is also limited by different policies of national health systems and high costs.

The consensus conference of the Society for Translational Medicine on postoperative management of EGFR-mutant lung cancer was focused on the management of mutated EGFR NSCLC after surgical resection (3). Beyond the members of the Society, several international experts were consulted to have a wider insight on the subject. The results of the consensus conference together with the opinions of the international experts reflect the broad heterogeneity in the management of these patients between different countries.

Several trials [such as RADIANT (4), the ADJUVANT/ CTONG1104 (5) and the EVAN (6)] explored the efficacy and safety of new tyrosine kinase inhibitors (TKI) like erlotinib in different setting on a different subset of patients in addition to standard cisplatin-based chemotherapy and built a good amount of high-grade evidence for their current use. The consensus conference focused on several aspects of the current management of post-surgical NSCLC, proposing some dedicated changes for those with mutated EGFR.

First of all, the consensus statement number 1 affirms that EGFR mutation should be tested in all patients with a radically resected non-squamous NSCLC. Although the strength of recommendation was considered strong, the opinion of international experts was not unanimous. As a matter of fact, EGFR mutation analysis is usually recommended in case of advanced non-squamous NSCLC or in case of young, non-smoker patients with squamous NSCLC, but a routine evaluation in case of early-stage or when adjuvant treatment is not indicated is not clearly supported by the current evidence. In some cases, EGFR analysis might be postponed and performed only in case of recurrence. The choice of testing patients for EGFR 
is strictly dependent on national health systems policies on reimbursement and the availability of TKI in different countries. Concurrently, consensus statement number 7 focused on histological material retrieval in case of recurrence or metastasis. In these cases, it is generally preferred a new analysis of EGFR status directly on the tissue of the recurrence or metastasis, if possible. EGFR mutation status on the specimen of primary cancer should be used only in case a new biopsy cannot be performed. Moreover, liquid biopsy could also be used as an alternative to evaluating EGFR mutations. Nevertheless, further biopsies of recurrence or metastatic sites might be complicated by the patient performance status or by the location of the new lesion, while liquid biopsies might be limited by laboratories' capability to perform these types of tests. Recently, studies on CT and PET/CT images opened new perspectives on radiomic; the parameters derived by the study of PET images can be used to verify the presence of mutations $(7,8)$ and therefore to assess the molecular status avoiding invasive procedures or they can also be used to verify the response to target therapies (9).

Nevertheless, routine analysis of EGFR mutation status is supported by the consensus statement number 6 , which strongly suggests differentiating the follow-up and the surveillance scheme for patients with EGFR mutation. This statement is based on the evidence that NSCLC harboring EGFR mutation had a significantly higher propensity to develop brain and bone metastasis (3). On the other hand, current European or American guidelines do not support differentiation of follow up strategies according to the EGFR status, but only according to the stage $(10,11)$. Moreover, brain metastasis is often clearly symptomatic and they might be investigated only after symptoms appear. It must be said that in Asia the percentage of non-squamous NSCLC harboring an EGFR mutation is significantly higher compared to Europe or the United States (12) and this difference might lead to the increased attention of consensus conference extensors to define different pathways of treatment and surveillance for these patients.

Lastly, the consensus statement number 4 suggests the possibility to replace chemotherapy with TKI in an adjuvant setting for patients with EGFR mutation. Although this should be considered an option for patients with lowperformance status, data supporting this statement are controversial and the opinions of international experts highlight different behavior on this subject, stressing the importance in terms of efficacy of chemotherapy also in patients with EGFR mutations.

From the perspective of a tumor- and patient-tailored therapeutic approach, a possible interesting future development in research would be a possible preoperative evaluation of EGFR and neoadjuvant TKI treatment, which has seldom been reported in the literature (13). As a matter of fact, as it is suggested by some preliminary results on neoadjuvant immunotherapy (14), in selected patients with particular mutations, a preoperative treatment might result in better long-term control of the disease.

In conclusion, EGFR mutated patients represent a subgroup of patients who might require a different therapeutic approach, regardless of their histology. They own different characteristics in terms of the pattern of recurrence, long-term outcomes and therapeutic options. Further studies with head to head comparison between chemotherapy and TKI in a different subset of patients (adjuvant treatment after surgery, definitive therapy for advanced stage, therapy in case of post-surgical relapse) are still needed to better define subgroups and to find the best therapeutic and surveillance schemes to follow.

\section{Acknowledgments}

Funding: None.

\section{Footnote}

Conflicts of Interest: All authors have completed the ICMJE uniform disclosure form (available at http://dx.doi. org/10.21037/jtd-2020-49). The authors have no conflicts of interest to declare.

Ethical Statement: The authors are accountable for all aspects of the work in ensuring that questions related to the accuracy or integrity of any part of the work are appropriately investigated and resolved.

Open Access Statement: This is an Open Access article distributed in accordance with the Creative Commons Attribution-NonCommercial-NoDerivs 4.0 International License (CC BY-NC-ND 4.0), which permits the noncommercial replication and distribution of the article with the strict proviso that no changes or edits are made and the original work is properly cited (including links to both the formal publication through the relevant DOI and the license). See: https://creativecommons.org/licenses/by-nc$\mathrm{nd} / 4.0 /$. 


\section{References}

1. Siegel RL, Miller KD, Jemal A. Cancer statistics, 2020. CA Cancer J Clin 2020;70:7-30.

2. Travis WD, Brambilla E, Nicholson AG, et al. The 2015 World Health Organization Classification of Lung Tumors: Impact of Genetic, Clinical and Radiologic Advances Since the 2004 Classification. J Thorac Oncol 2015;10:1243-60.

3. Liang W, Cai K, Chen C, et al. Society for Translational Medicine consensus on postoperative management of EGFR-mutant lung cancer (2019 edition). Transl Lung Cancer Res 2019;8:1163-73.

4. Kelly K, Altorki NK, Eberhardt WE, et al. Adjuvant Erlotinib Versus Placebo in Patients With Stage IBIIIA Non-Small-Cell Lung Cancer (RADIANT): A Randomized, Double-Blind, Phase III Trial. J Clin Oncol 2015;33:4007-14.

5. Zhong WZ, Chen KN, Chen C, et al. Erlotinib Versus Gemcitabine Plus Cisplatin as Neoadjuvant Treatment of Stage IIIA-N2 EGFR-Mutant Non-Small-Cell Lung Cancer (EMERGING-CTONG 1103): A Randomized Phase II Study. J Clin Oncol 2019;37:2235-45.

6. Yue D, Xu S, Wang Q, et al. Erlotinib versus vinorelbine plus cisplatin as adjuvant therapy in Chinese patients with stage IIIA EGFR mutation-positive non-small-cell lung

Cite this article as: Bertoglio P, Costardi L, Viti A, Ruffini E, Guerrera F. It takes all sorts to make a world: geographical differences and the future perspective of molecular testing in non-small cell lung cancer. J Thorac Dis 2020;12(9):5050-5052. doi: $10.21037 /$ jtd-2020-49 cancer (EVAN): a randomised, open-label, phase 2 trial. Lancet Respir Med 2018;6:863-73.

7. Li X, Yin G, Zhang Y, et al. Predictive Power of a Radiomic Signature Based on 18F-FDG PET/CT Images for EGFR Mutational Status in NSCLC. Front Oncol 2019;9:1062.

8. Zhang J, Zhao X, Zhao Y, et al. Value of pre-therapy 18F-FDG PET/CT radiomics in predicting EGFR mutation status in patients with non-small cell lung cancer. Eur J Nucl Med Mol Imaging 2020;47:1137-46.

9. Benz MR, Herrmann K, Walter F, et al. (18)F-FDG PET/ CT for monitoring treatment responses to the epidermal growth factor receptor inhibitor erlotinib. J Nucl Med 2011;52:1684-9.

10. Available online: www.nccn.org

11. Available online: www.nice.org.uk

12. Mitsudomi T. Molecular epidemiology of lung cancer and geographic variations with special reference to EGFR mutations. Transl Lung Cancer Res 2014;3:205-11.

13. Parikh AB, Hammons L, Gomez JE. Neoadjuvant Tyrosine Kinase Inhibition in Locally-advanced Nonsmall Cell Lung Cancer: Two Cases and a Brief Literature Review. Anticancer Res 2019;39:897-902.

14. Forde PM, Chaft JE, Pardoll DM. Neoadjuvant PD-1 Blockade in Resectable Lung Cancer. N Engl J Med 2018;379:e14. 